\title{
Growth impairment in children treated for brain tumours
}

\author{
S. M. SHALET, C. G. BEARDWELl, B. M. AARONS, D. PEARSON, AND \\ P. H. MORRIS JONES
}

From the Departments of Endocrinology and Paediatric Oncology, Christie Hospital and Holt Radium Institute, Manchester

SUMMARY Growth and growth hormone (GH) secretion were studied in 14 children with brain tumours before radiation and chemotherapy and at various time intervals afterwards. The peak GH response to hypoglycaemia was normal in all patients before radiation. In 6 patients the peak GH response was impaired 1 year after radiation, and in a seventh it was normal at 1 year but impaired 2 years after radiation. In 12 of 13 patients the growth velocity during the first year of chemotherapy was below the 3rd centile, although none of these had an initial standing height below the 3rd centile. Thus it appears that poor growth in such children occurs irrespective of whether radiation-induced GH deficiency develops. The cause of this impaired growth is unknown.

It has been shown in several studies (Onoyama et al., 1975; Bamford et al., 1976) that patients treated in childhood for brain tumours are commonly of short stature in later life. The majority of these patients are currently treated by surgery, external irradiation, and cytotoxic drugs. The radiotherapy may interfere with growth in two ways: spinal irradiation may impair spinal growth (Probert et al., 1973), and cranial irradiation may cause growth hormone (GH) deficiency (Shalet et al., 1976). It is not known, however, at what stage after treatment the GH deficiency becomes clinically obvious, nor whether chemotherapy affects growth. We studied growth rate and GH secretion in a group of children with brain tumours before radiation and chemotherapy, then at various time intervals afterwards.

\section{Patients and methods}

Fourteen children were studied, 6 boys and 8 girls. Their ages at the time of radiation ranged from 1.8 to $14 \cdot 3$ years. The original brain tumours included 6 medulloblastoma, 4 glioma, 3 ependymoma, and 1 undifferentiated primary brain tumour. All tumours were anatomically distant from the hypothalamicpituitary region. In 12 patients either partial or total neurosurgical removal of the tumour was performed. All cases received cranial radiation and in 9 the spine was irradiated as well. The radiation dose reaching Received 10 Novemter 1977 the hypothalamic-pituitary axis was calculated as previously described (Shalet et al., 1976). All patients except one received chemotherapy on a 6weekly basis with either bischloronitrosourea (BCNU) alone, or BCNU and vincristine. Those who received BCNU alone every 6 weeks also received 3 injections of vincristine shortly after neurosurgery was complete. The total duration of chemotherapy was 2 years and in some cases has not been completed yet. The age at initial treatment, sex, pathological diagnosis, dose of irradiation to the hypothalamicpituitary region, and chemotherapy used are given in Table 1.

All patients were clinically healthy at the time of endocrine studies and none showed evidence of illhealth or signs of recurrent tumour during the follow-up period. Standing and sitting heights were measured with a Harpenden stadiometer. Bone age was estimated using the method of Tanner et al. (1975). Tests of pituitary function were done, after an overnight fast, between 9 and 10 a.m. A combined insulin tolerance test and thyrotrophin releasing hormone (TRH) test was carried out as described previously (Shalet et al., 1975). Basal blood samples were also taken for measurement of thyroxine (T4), triiodothyronine (T3), prolactin, follicle-stimulating hormone (FSH), and luteinising hormone (LH).

The auxological data were obtained and endocrine studies performed on the children after neurosurgery and immediately before radiation treatment. 
Table 1 Age at initial treatment, sex, pathological diagnosis, and details of therapy

\begin{tabular}{|c|c|c|c|c|c|}
\hline Case no. & Sex & $\begin{array}{l}\text { Age at initial } \\
\text { treatment (years) }\end{array}$ & Pathological diagnosis & $\begin{array}{l}\text { Dose of irradiation to } \\
\text { hypothalamic-pitu tary } \\
\text { region (rads) }\end{array}$ & Chemotherapy \\
\hline $\begin{array}{l}1 * \\
2 \\
3 \\
4^{*} \\
5 \\
6^{*} \\
7^{*} \\
8^{*} \\
9^{*} \\
10^{*} \\
11^{*} \\
12 \\
13 \\
14^{*}\end{array}$ & $\begin{array}{l}\mathbf{M} \\
\mathbf{F} \\
\mathbf{M} \\
\mathbf{F} \\
\mathbf{F} \\
\mathbf{F} \\
\mathbf{M} \\
\mathbf{F} \\
\mathbf{M} \\
\mathbf{F} \\
\mathbf{M} \\
\mathbf{M} \\
\mathbf{F} \\
\mathbf{F}\end{array}$ & $\begin{array}{r}8 \cdot 3 \\
8 \cdot 6 \\
4 \cdot 8 \\
1 \cdot 8 \\
7 \cdot 4 \\
11 \cdot 9 \\
11 \cdot 3 \\
14 \cdot 3 \\
7 \cdot 4 \\
6 \cdot 6 \\
8 \cdot 4 \\
11 \cdot 5 \\
12 \cdot 2 \\
3 \cdot 2\end{array}$ & $\begin{array}{l}\text { Medulloblastoma } \\
\text { Undifferentiated primary } \\
\text { brain tumour } \\
\text { Glioma } \\
\text { Medulloblastoma } \\
\text { Glioma } \\
\text { Ependymoma } \\
\text { Ependymoma } \\
\text { Ependymoma } \\
\text { Medulloblastoma } \\
\text { Medulloblastoma } \\
\text { Medulloblastoma } \\
\text { Glioma } \\
\text { Glioma } \\
\text { Medulloblastoma }\end{array}$ & $\begin{array}{l}2700 \\
3750 \\
780-3470 \\
3200 \\
3750 \\
2700 \\
3200 \\
2700 \\
2700 \\
3200 \\
2700 \\
4500 \\
0 \\
2700\end{array}$ & $\begin{array}{l}\text { BCNU + vincristine } \\
\text { BCNU + vincristine } \\
\text { None } \\
\text { BCNU + vincristine } \\
\quad " \text { + vincrinstine } \\
" \text { + vincristine } \\
" \text { + vincristine } \\
" \text { + vincristine } \\
" \quad \\
" \quad+\text { vincristine }\end{array}$ \\
\hline
\end{tabular}

*Patient received spinal irradiation.

BCNU = bischloronitrosourea.

In all cases the measurements were repeated approximately 1 year later, and in 3 children we have the results of hormonal studies 2 years after the initial treatment.

The measurement of the glucose, cortisol, $\mathrm{GH}$, TSH, T3, T4, FSH, and LH levels are described elsewhere (Shalet et al., 1975). Serum prolactin was measured by double antibody radioimmunoassay using MRC standard 71/222 (McNeilly, 1973).

\section{Results}

Table 2 shows the peak GH responses to insulin hypoglycaemia before irradiation and chemotherapy, 1 year later, and in a few cases 2 years later. Similar degree of hypoglycaemia, both clinically and biochemically were obtained in the subjects at the different study times and the dose of insulin used was constant. The peak GH response to hypoglycaemia was normal in all patients before radiation (normal $\geqslant 20 \mathrm{mU} / \mathrm{l}$ ). In 6 the peak $\mathrm{GH}$ response to the insulin tolerance test was impaired 1 year after radiation and in a seventh (Case 8) the peak GH response was normal at 1 year but impaired 2 years after radiation. In the latter patient the abnormalities have been further confirmed by repeat provocation tests 3 years after radiation at which time the peak GH response to an insulin tolerance test remained subnormal $(5.9 \mathrm{mU} / \mathrm{l})$ and there was no detectable GH response to arginine.

The standing heights of the children were assessed before radiation and the centile position for each obtained from standard charts (Tanner and Whitehouse, 1976). Growth velocity during the first year of chemotherapy was calculated using the chronological age. 12 children had a growth velocity below the 3rd centile although none of these had an initial standing height below the 3rd centile. Case 3, the

Table 2 Peak $G H$ responses to insulin tolerance test (ITT), growth data, and bone ages

\begin{tabular}{|c|c|c|c|c|c|c|c|c|}
\hline \multirow[t]{2}{*}{ Case no. } & \multicolumn{3}{|c|}{$\begin{array}{l}\text { Peak GH response to } I T T \\
(m U / l)^{*}\end{array}$} & \multirow[t]{2}{*}{$\begin{array}{l}\text { Initial standing } \\
\text { height (centile) }\end{array}$} & \multirow{2}{*}{$\begin{array}{l}\text { Change in } \\
\text { standing height } \\
\text { during first year } \\
\text { of treatment }(\mathrm{cm})\end{array}$} & \multirow{2}{*}{$\begin{array}{l}\text { Growth velocity } \\
\text { during first year } \\
\text { of treatment } \\
\text { (centile) }\end{array}$} & \multirow{2}{*}{$\begin{array}{l}\text { Initial TW2 } \\
\text { 20-bone bone age } \\
\text { (years) } \dagger\end{array}$} & \multirow{2}{*}{$\begin{array}{l}\text { Advance in bone } \\
\text { age during first } \\
\text { year of treatment } \\
\text { (years) }\end{array}$} \\
\hline & $I$ & 2 & 3 & & & & & \\
\hline 1 & 52 & 35 & - & $50-75$ & $2 \cdot 3$ & $<3$ & $7 \cdot 1$ & 0.4 \\
\hline 2 & 40 & 7 & $12 \ddagger$ & 10 & $3 \cdot 3$ & $<3$ & $7 \cdot 2$ & 0.6 \\
\hline 3 & 53 & 39 & 29 & 10 & $5 \cdot 0$ & 10 & $5 \cdot 3$ & 0.7 \\
\hline 4 & 63 & 9 & - & $75-90$ & $5 \cdot 0$ & $<3$ & $2 \cdot 3$ & 0.9 \\
\hline 5 & 22 & 12 & - & $50-75$ & 2.9 & $<3$ & $7 \cdot 2$ & 0.5 \\
\hline 6 & 63 & 17 & - & $25-50$ & $1 \cdot 2$ & $<3$ & 13.4 & 0.5 \\
\hline 7 & 70 & 14 & - & $3-10$ & $2 \cdot 5$ & $<3$ & $10 \cdot 8$ & 0.8 \\
\hline 8 & 33 & 40 & 4 & $10-25$ & 0.8 & - & Adult & - \\
\hline 9 & 53 & 18 & - & $50-75$ & $2 \cdot 9$ & $<3$ & $8 \cdot 2$ & 0.5 \\
\hline 10 & 22 & 40 & - & 10 & $3 \cdot 5$ & $<3$ & $7 \cdot 8$ & 0.5 \\
\hline 11 & 20 & 22 & - & $75-90$ & $1 \cdot 4$ & $<3$ & $8 \cdot 8$ & $1 \cdot 1$ \\
\hline 12 & 85 & 37 & - & $10-25$ & $2 \cdot 8$ & $<3$ & $11 \cdot 5$ & $0 \cdot 3$ \\
\hline 13 & 26 & 30 & - & $10-25$ & $1 \cdot 8$ & $<3$ & $11 \cdot 9$ & 0.8 \\
\hline 14 & 62 & 62 & - & $10-25$ & $3 \cdot 4$ & $<3$ & $4 \cdot 3$ & 0.9 \\
\hline
\end{tabular}

* Studies performed: 1 = before cranial radiation; $2=$ one year later; $3=2$ years later.

†Tanner et al. (1975).

$\ddagger$ On this occasion arginine stimulation test performed. 
only patient who did not receive chemotherapy, had a growth velocity on the 10th centile as was his initial standing height. In Case 8 menarche took place over 4 years before the brain tumour was diagnosed and growth had effectively ceased at the time of the study. Growth velocity data were only available in 4 patients for the second year of chemotherapy. 3 of the 4 continued to grow at a rate below the 3rd centile and in the fourth growth velocity increased during the second year of chemotherapy to lie between the 25-50th centile. Bone age estimations were performed before and 1 year after radiation in all subjects and the results are shown in Table 2. In all but one, who had an adult bone age before therapy, definite advancement of the bone age took place over the 12-month period; however, the mean change in bone age for the group was only 0.7 years. At the end of 1 year, out of 9 subjects who received spinal irradiation 1 showed skeletal disproportion consistent with impaired spinal growth not present when the patient was first measured before radiation.

All patients were clinically and biochemically euthyroid both before and 1 year after radiation. The remainder of pituitary function was normal in all except 4 girls who showed a raised serum FSH level 1 year after radiation. 2 of these (Cases 2,6 ) exhibited pubertal changes during the first year of chemotherapy which may have accounted for the rise in FSH levels. The other 2 girls were much younger (Cases 4, 14) and the raised FSH levels could not be accounted for by pubertal development. Both of these girls received spinal irradiation and chemotherapy. The ovaries of similar cases, obtained at necropsy, may show morphological changes such as impaired follicular maturation (H. Peters and R. Himelstein-Braw, personal communication, 1976).

\section{Discussion}

Examination in children of the relationship between radiation dose received by the hypothalamicpituitary region and GH responses to hypoglycaemia 2 years after radiation suggested that a minimum dose of 2500-2900 rads was needed to produce GH deficiency (Shalet et al., 1976). In this study 12 children received a radiation dose of 2700 rads or more, and 1 year after radiation 6 showed significantly impaired GH responses to hypoglycaemia, but showed a normal GH response when tested before radiation. Thus the impression that cerebral irradiation is a potent cause of GH deficiency is confirmed and we note that biochemical evidence of GH deficiency has appeared in $50 \%$ of potential cases within 1 year of radiation. Furthermore, as Case 8 is known to have normal GH responses at
1 year but impaired GH responses 2 and 3 years after radiation, the remaining children may show biochemical evidence of GH deficiency in the future.

The most striking finding in this study is that 12 of the 13 children in whom growth could be assessed in the first year after irradiation grew very poorly. The only exception was Case 3 whose growth continued along the 10th centile. He was the only patient who did not receive chemotherapy and although this might suggest that chemotherapy produced growth retardation it should be noted that one patient showed an increased growth velocity during the second year of treatment while chemotherapy was continuing. Children whose GH secretion appeared to remain adequate over the first year of study grew just as poorly as those who developed GH deficiency. Furthermore there was no difference in the mean bone age change over the first 12 months of treatment between the children with impaired GH responses (mean $=0.63$ years) and those with normal $\mathrm{GH}$ responses (mean $=0.67$ years).

The cause of growth retardation at this stage of treatment remains obscure. Though all patients appeared well during the study period, some clearly had residual tumour which might have interfered with growth in some way. This explanation, however, would probably not apply to all children in the group. It has been suggested that in the rat (Mosier and Jansons, 1967, 1968, 1970) cerebral irradiation may interfere with growth independently of an endocrine mechanism but how this effect is mediated is unknown. Finally, in spite of the objections outlined above, it cannot be assumed that chemotherapy may not interfere with somatomedin production, activity, or cartilage metabolism.

Whatever the cause of the growth impairment, the practical conclusion of this study is that poor growth within one year of treatment of a brain tumour cannot be assumed to indicate GH deficiency. Nor can it be assumed that while chemotherapy is continued GH treatment will produce an increased growth velocity in children in whom biochemical evidence of GH deficiency is present. However, GH deficiency certainly contributes to the impaired growth rates seen in some children several years after cranial radiation. We have treated 6 such children with radiation-induced GH deficiency with GH. These children were treated between 3 and 10 years after $x$-ray therapy. The mean growth during the pretreatment year was $3.7 \mathrm{~cm}$ and during the first year of GH therapy $7 \cdot 9 \mathrm{~cm}$.

We thank Mrs A. Hurst for secretarial assistance. This work was supported in part by grants from the North Western Regional Health Authority and the Leukaemia Research Fund. 


\section{References}

Bamford, F. N., Morris-Jones, P. H., Pearson, D., Ribeiro, G. G., Shalet, S. M., and Beardwell, C. G. (1976). Residual disabilities in children treated for intracranial spaceoccupying lesions. Cancer, 37, 1149-1151.

McNeilly, A. S. (1973). Radioimmunoassay of human prolactin. Proceedings of the Royal Society of Medicine, 66, 863-864.

Mosier, H. D., Jr., and Jansons, R. A. (1967). Stunted growth in rats following X-irradiation of the head. Growth, 31, 139-148.

Mosier, H. D., Jr., and Jansons, R. A. (1968). Pituitary content of somatotropin, gonadotropin and thyrotropin in rats with stunted linear growth following head X-irradiation. Proceedings of the Society for Experimental Biology and Medicine, 128, 23-26.

Mosier, H. D., Jr., and Jansons, R. A. (1970). Effect of Xirradiation of selected areas of the head of the newborn rat on growth. Radiation Research, 43, 92-104.

Onoyama, Y., Abe, M., Takahashi, M., Yabumoto, E., and Sakamoto, T. (1975). Radiation therapy of brain tumours in children. Radiology, 115, 687-693.
Probert, J. C., Parker, B. R., and Kaplan, H. S. (1973). Growth retardation in children after megavoltage irradiation of the spine. Cancer, 32, 634-639.

Shalet, S. M., Beardwell, C. G., Morris-Jones, P. H., and Pearson, D. (1975). Pituitary function after treatment of intracranial tumours in children. Lancet, 2, 104-107.

Shalet, S. M., Beardwell, C. G., Pearson, D., and MorrisJones, P. H. (1976). The effect of varying doses of cerebral irradiation on growth hormone production in childhood. Clinical Endocrinology, 5, 287-290.

Tanner, J. M., and Whitehouse, R. H. (1976). Clinical longitudinal standards for height, weight, height velocity, weight velocity, and stages of puberty. Archives of Disease in Childhood, 51, 170-179.

Tanner, J. M., Whitehouse, R. H., Marshall, W. A., Healy, M. J. R., and Goldstein, H. (1975). Assessment of Skeletal Maturity and Prediction of Adult Height (TW2 Method). Academic Press, London.

Correspondence to Dr S. M. Shalet, Department of Endocrinology, Christie Hospital and Holt Radium Institute, Withington, Manchester M20 9BX. 